sensory and motor quite tentatively, and preferably to speak of these so-called cortical centres as areas of the nervous system through which pass certain sensori-motor loops, and whose destruction will render impossible the productions of those muscular movements, etc. which had previously depended upon their existence.

Dr. Mercier.

Before entering on this discussion, may I first be permitted to express the sense of incongruity which it arouses? It appears to mo that a discussion by the Neurological Society, as to whether or not the idea of movement is a concomitant of the ontgoing current, bears a certain analogy to a discnssion by the Astronomical Society as to whether or not the earth is round.

Dr. Bastian has complained that there has been shown no $a$ priori reason why the generally received doctrine should be preferred to his own, which I with difficulty refrain from calling the geocentric doctrine of neurology. This is a complaint which he ought not to have the opportunity of making again, and for want of a better I will supply him with an argument wbich is, I hope, not open to objections on the score of deficiency in $\grave{a}$ priori character. The organism exists not alone in space, but in the midst of surroundings. Between it and its surroundings but two actions are passible, viz. action of the surroundings on the organism, and action of the organism on its surroundings. These two actions are of co-ordinate importance. Consciousness cannot exist without both. Life cannot exist without both. Into every manifestation of consciousness and into every manifestation of life buth elements enter as necessary constituents. We may separate them in analysis, but in fact they are inseparable. In the constitution of conscionsness and of life neither of these elements is hefore nor after the other, ifeither is greater nor less than the other. Yet, according to Dr. Bastian, the actions of the environment on the organism are known immediately and directly, while the actions of the organism on the environment are known only mediately and indirectly and subordinately and at second hand.

Much has been said as to whether this or that case has been accurately observed and correctly reported, and as to whether this or that fact may not be capable of a different interpretation from that which Dr. Bastian places on it. I am not concerned to enter on these matters, and I will say at once that I will make Dr. Bastian a present of all his facts. I will take his doctrine as he himself states it, and show, not merely that he has made out no case to be answered, but that he himself explicitly admits the accuracy. and truth of the orthodox viow. 
Dr. Bastian says that these cortical centres are not the real motor centres. The real motor centres are in the cord and medulla. But what does he mean by a real motor centre? Those only, it appears, which co-ordinate muscular actions into movements. This alone is what Dr. Bastian calls co-ordination. But this is only one case of co-ordination. The combination of movements into acts is a case of co-ordination, and is effected by centres higher than those in the curd. The cumbination of acts into operations is a case of co-ordination, and is affected by centres higher than the last. The combination of operatiuns into conduct is a further instance of co-ordination, and is effected by the highest centres of all. Every one of these co-ordinations is a coordination of movement, is a motor process, and is effected by motor centres. However, I do not desire to be exacting, and I will admit, for the sake of argument, that the only real motor centres are in the spinal cord.

Dr. Bastian's next point is that the cortical centres are not motor, but sensory. They are not motor, because, as we have just seen, the influence descending from them to the periphery has to act through other centres before producing movement. But is it pretended that sensory impressions on their way to the cortex are not co-ordinated and re-co-ordinated and co-ordinated again? and that in undergoing this process they have not to pass through centre after centre? If the motor centres are not motor because other centres intervene between them and the periphery, then for the same reason the sensory centres are not sensory. However, I will yield this point also, and will grant Dr. Bastian all his data, submit to all his arguments, and show that his conclusions, so far from being adverse to the generally-received doctrine, are in fact entirely in harmony with it and corroborative of it.

Dr. Bastian admits that the centres in dispute are the turningpoint of the nerve current. He admits that although they are not motor centres, yet from them issue "volitional motor incitations." These volitional motor incitations descend to the "real" motor centres and set them in action, and hence arise movements. Here I have Dr. Bastian on the horns of a dilemma.

What is it that descends to the motor centres? A volitional motor incitation, (p. 87). A volitional impulse, (p. 54). What is that? Does Dr. Bastian mean that the will sits enthroned in the cortical centres and from thenco directs the operations that go on in the brain? Does he mean that the will itself passes down the nerve fibres and discharges the cells of the lower centres? He has expressly repudiated any such absurdity. But if he escapes from this horn of the dilemma it is only to be impaled on the other. 
If it be not a state of mind that descends to the cortical from the "real" motor centres, then it must be a physical process, a nervous discharge, or nerve current, or molecular movement of some kind. Now mark : this current is an efferent current; it is an efferent current which really is (p. 86) a motor incitation; that is to say, which results in a movement. And this efferent current is also a "volitional impulse;" that is to say, the nerrous action is attended by the mental act of willing. Of willing what? A movement. In other words, this "volitional impulse," which on its physical side is an outgoing current, is on its mental side a volition of movement. Now it cannot be contended for a moment that an idea of movement does not form part of a volition of movement. I cannot will to walk across the room without having an idea of walking across the room. So that, according to Dr. Bastian's own statement, the idea of movement is a concomitant of the outgoing current, and this doctrine, which he set himself down to disprove, he has laboriously established beyond all risk of confutation. Like Balaam, the son of Beor, he took up his parable to curse, and he has blessed us altogether.

\section{DR. DE WATTEVille.}

From the discussion that precedes, we gather that those who refuse representation in consciousness to the purely moter, or outgoing, processes of the cortex, are not agreed as to the nature of the Rolandio area. Whilst Dr. Ferrier considers it as the cortical equivalent of the anterior horns of the spinal cord, Dr. Bastian argues for its sensory, or rather receptive, character, and attributes to it kinæsthetic functions, implying by this word that the so-called motor convolutions are the end stations of sub-conscious centripetal impulses from the organs of movement.

Between these two views that of Dr. Ross forms a transition. According to him, the large cells of the Rolandic area are truly motor, whilst the small cells are receptive, perhaps even sensory.

I do not propose to enter upon this aspect of the question now before us, for the simple reason, that I scarcely feel competent to discuss a point so full of difficulty. But I accept ss more consonant with the facts the view held in common by the distinguished neurologists just named, and shared by many of the leading psychologists abroad, that the physical substrata of volition, of the leelings of effort and movement, are antecedent processes to the final, or "motor" cerebral discharge. Dr. Mercier has just given expression, in terms more lively than forcible, to a diametrically opposite opinion. He calls our position a "geocentric" one. I should have thought that, if anything deserved 